\title{
Unmet needs, health policies, and actions during the COVID-19 pandemic: a report from six European countries
}

\author{
Oriol Miralles ${ }^{1}\left[\mathbb{C}^{\circ}\right.$. Dolores Sanchez-Rodriguez ${ }^{2,3,4}$. Esther Marco ${ }^{5}$. Cédric Annweiler ${ }^{6,7,8}$. Ainhoa Baztan ${ }^{9}$. \\ Évora Betancor ${ }^{1}$. Alicia Cambra ${ }^{1}$ Matteo Cesari ${ }^{10,11}$ - Benito J. Fontecha ${ }^{1}$. Jerzy Gąsowski ${ }^{12}$. Sophie Gillain ${ }^{13}$. \\ Suzy Hope ${ }^{14,15} \cdot$ Katie Phillips $^{16} \cdot$ Karolina Piotrowicz $^{12}$. Niccolò Piro ${ }^{10}$. Guillaume Sacco ${ }^{6,7}$. Edoardo Saporiti ${ }^{10}$. \\ Murielle Surquin $^{16,17} \cdot$ Estel Vall-Ilosera $^{1}$
}

Received: 15 July 2020 / Accepted: 29 September 2020

(c) European Geriatric Medicine Society 2020, corrected publication 2021

\section{Key summary points}

Aim To assess the impact on the older population of policies to decrease the overall impact of the COVID-19 pandemic in Europe.

Findings Ageism has occurred during the COVID-19 pandemic.

Message Analysis of the effects of the COVID-19 pandemic on the older population will help us to develop fairer and more inclusive policies in the future.

\begin{abstract}
Purpose The United Nations (UN) has published a Policy Brief on the impact of the Coronavirus Disease 2019 (COVID-19) that identifies policies and responses to protect older adults. Our objective was to summarize actions, health policies and clinical guidelines adopted by six European countries (Belgium, France, Italy, Poland, Spain and United Kingdom) during the pandemic, and to assess the impact of national policies on reducing adverse effects of the COVID-19 pandemic in older populations.

Methods Reports by geriatricians on the measures and actions undertaken by governmental institutions in each country between March and July 2020, as well as the role of primary care during the pandemic, covered three areas: (a) general health strategies related to the pandemic; (b) impact of COVID-19 on health inequity; and (c) initiatives and challenges for the COVID-19 pandemic and beyond.

Results In the six countries, COVID-19 mortality in nursing homes ranged from 26 to $66 \%$. Although all countries endorsed the World Health Organization general recommendations, the reports identified the lack of harmonized European guidelines and policies for nursing homes, with competencies transferred to national (or regional) governments. All countries restricted visits in nursing homes, but no specific action plans were provided. The role of primary care was limited by the centralization of the crisis in hospital settings.

Conclusions The older population has been greatly affected by COVID-19 and by the policies initiated to control its spread. The right to health and dignity are transgenerational; chronological age should not be the sole criterion in policy decisions.
\end{abstract}

Keywords COVID-19 $\cdot$ Ageism $\cdot$ SARS-CoV-2 $\cdot$ Older people $\cdot$ Geriatrics $\cdot$ Health policies

\section{Background}

Dolores Sanchez-Rodriguez and Esther Marco Shared second authorship.

Oriol Miralles

o.mirallesresina@gmail.com

Extended author information available on the last page of the article
The first cases of Severe Acute Respiratory Syndrome Coronavirus 2 (SARS-CoV-2) were reported in December 2019 in Wuhan, China, causing an outbreak of coronavirus disease (COVID-19). Since then, SARS-CoV-2 has spread across 213 countries in all continents, causing a serious public health crisis. Despite the worldwide implementation of 
public health measures recommended by the World Health Organization (WHO), such as contact tracing, social distancing and mass testing, there had been 10,357,662 confirmed cases with a total of 508,055 as of 1st July 2020. Over two million of these cases and nearly 200,000 of the deaths were in Europe [1].

European countries have the largest percentage of the older population in the world. Increased age has been associated with worse outcomes in COVID-19: older adults are more susceptible to the infection and have a significantly higher risk of severe disease and serious complications. Moreover, $95 \%$ of deaths from COVID-19 have occurred in those older than 60 , and $50 \%$ in people aged 80 or older [2]. The main reasons suggested for the more severe effects of COVID-19 on the older population include the physiological changes associated with ageing, decreased age-related immune function and the presence of frailty (COVID-19 frailty spiraling syndrome) [3]. Other geriatric syndromes such as cognitive decline or a reduced performance in activities of daily life play an important role in older patients' ability to cope with severe stressors such as critical illness, and might have influenced the higher rates of clinical adverse outcomes during the COVID-19 crisis.

The characteristics of the healthcare systems and the sociodemographic needs of the different European countries vary widely, and the measures recommended by the WHO (summarized in Fig. 1) have been applied differently across different countries and regions. Aware of the risks and potential inequalities in access to healthcare, the United Nations (UN) launched the UN Policy Brief: 'The Impact of COVID-19 in Older Persons', a report about health policies to ensure meeting the needs of older populations, especially the most vulnerable [4]. The European Union Geriatric Medicine Society (EuGMS) joined the UN effort and gathered the COVID-19 Task Force, which promotes collaborative initiatives from the Geriatrics and the National Societies across Europe [5]. Our working group has followed this call to action to ponder the failures and successes of our responses to COVID-19 pandemic. Our initiative seeks to identify points for further improvement to ensure the highest quality of care for older adults across European countries with the perspective of a second wave or in case COVID-19 is here for the long haul [6].

Our objective in the present analysis was to compile a brief summary of the actions, health policies and clinical guidelines adopted by six European countries (Belgium, France, Italy, Poland, Spain and United Kingdom) between March and July 2020. Secondly, we discussed their impact on the older population following the four key priorities outlined in the UN Policy Brief:

1. Right to health and participation in the decision-making process.

2. Social inclusion and solidarity under conditions of physical distancing.

3. Necessity to provide adequate and correctly funded care and support services for older adults.

4. Expand participation by older adults, share good practice and harness knowledge and data.

\section{Methods}

This is a narrative review and authors' opinion on the impact of the COVID-19 pandemic on the older population in Belgium, France, Italy, Poland, Spain and United Kingdom between March and July 2020. A research group from Barcelona formulated the aim of developing a European working group representative of specialists in Geriatric Medicine. These specialists were asked to provide a
Fig. 1 WHO general recommendations to prevent infection and transmission of COVID-19
General measures to prevent transmission of COVID-19

- Wash your hands regularly with soap and water, or clean them with alcoholbased hand rub.

- Maintain at least 1 metre distance between you and people coughing or sneezing.

- Avoid touching your face.

- Cover your mouth and nose when coughing or sneezing.

- Stay home if you feel unwell.

- Refrain from smoking and other activities that weaken the lungs.

- Practice physical distancing by avoiding unnecessary travel and staying away from large groups of people. 
report on the COVID-19 crisis in their respective countries, to include three areas: (1) response and difficulties related to the pandemic; (2) health inequity and the impact of COVID-19; and (3) initiatives and challenges for the COVID-19 pandemic and beyond. The information collected from the six national reports was pulled together and discussed following the key priorities for action outlined in the UN Policy Brief: (1) Right to health and the participation in the decision-making process; (2) Social inclusion and solidarity under conditions of physical distancing; (3) Necessity of adequate, correctly funded care and support services for older adults; and (4) Need to expand participation by older adults, share good practice and harness knowledge and data [4].

The literature search was conducted in MEDLINE (PubMed) and the Webpages of government health departments, international health organizations, consensus reports and general position statements from scientific societies.

\section{Results}

Between March and July 2020, high numbers of deaths from COVID-19 were recorded in four of the six participant countries (no data available for Italy and Poland). Reports from geriatricians detailed responses and difficulties related to the pandemic and the impact of the disease on health inequity in older adults in their respective countries. Initiatives and challenges to consider in preparation for a potential second wave of COVID-19 are discussed below. The measures implemented against COVID-19 in each country are summarized in Fig. 2, which offers a concise comparison of the actions taken.

\section{Experiences of six European countries}

\section{Belgium}

General health strategies related to the pandemic: The first cases in Belgium were detected on 2nd March [7], ten days before the WHO declared a pandemic on 12th March 2020. The website dedicated to COVID-19 launched by the National Institute of Epidemiology and Infectious Diseases (Sciensano) in the first week of March became an efficient communication tool during the crisis. On 17th March, Belgium endorsed the general WHO recommendations [1]. The strategy of the Belgian healthcare authorities was focused to prevent overload of hospital capacity, particularly in intensive care and emergency departments. In the Frenchspeaking region, the "Plan d'Urgence Hospitalier" was launched on 14th March and focused on ensuring distribution of hospital equipment, including personal protective equipment (PPE), and human resources (e.g., by reduction/ postponement of non-urgent surgical interventions and visits to outpatient clinics).

Impact of COVID-19 on health inequity: On 25th May, Belgium had reported 5734 people with confirmed SARSCoV-2 infection in long-term care facilities (LTCF). From a total of 9052 COVID-19 related deaths, 4616 (51\%) were in LTCF [8]. The nursing homes population was the most severely affected, probably due to the baseline health status of residents (higher comorbidity and frailty) and scarcity of resources. General governmental recommendations for the control of SARS-CoV-2 spread in nursing homes had been given, but not all of them could be implemented. The response of individual nursing homes depended on the local resources in terms of protection, isolation and medical care, which were shown to be insufficient when
Fig. 2 Comparison of selected measures specific to older adults implemented against COVID19 as of May 2020 in Belgium, France, Italy, Poland*, Spain and UK (Scotland, England, Wales)

\begin{tabular}{|r|cccccc|}
\hline & & & & & & \\
\hline WHO's general recommendations & $\bullet$ & $\bullet$ & $\bullet$ & $\bullet$ & $\bullet$ & $\bullet$ \\
\hline Enough stock of medical supplies & - & - & - & - & - & - \\
\hline Clinical guidelines specific to older people & - & - & - & $\bullet$ & - & $\bullet$ \\
\hline CGA-based treatment escalation plans & $\bullet$ & - & - & - & 0 & 0 \\
\hline Restricted visits in NHs & $\bullet$ & $\bullet$ & $\bullet$ & $\bullet$ & $\bullet$ & $\bullet$ \\
\hline Specific action plans for NHs & 0 & - & - & - & - & - \\
\hline Programmes enabling social networking & - & - & - & - & - & $\bullet$ \\
\hline
\end{tabular}

- Implemented; ○ Partially Implemented; - Not implemented or available.

* Guidelines recommended by the Polish Psychiatric Society focused on the care of patients with dementia.

Abbreviations: CGA: Comprehensive Geriatric Assessment; NH: nursing home. 
the demands exploded exponentially. New supplies perhaps became available too late: PPE distribution started on 26th March and systematic reverse transcription polymerase chain reaction (RT-PCR) testing for residents and workers on 10th April. The nursing homes registered each new case of COVID-19 as "suspected", "confirmed after RT-PCR test" or "deceased" during part of the crisis. This registration procedure made it difficult to accurately quantify and differentiate the number of COVID-19 related deaths from deaths related to worsening of previous chronic conditions or other acute processes, contributing to a general underestimation of the disease burden and mortality. Decision-making regarding whether to transfer patients from the community or nursing home setting to a hospital was not based on age, but on functional capacity, health status and previous wishes expressed by the patients or their representatives. Guidance to general practitioners regarding levels of therapeutic intensity and transfer decision-making came from scientific societies (e.g. the Belgian Society of Geriatrics and Gerontology [BSGG] and the Société Scientifique de Médecine Générale [SSMG]). The SSMG developed an algorithm based on Rockwood's Clinical Frailty Scale and semiology ("atypical" presentation of illness) of COVID-19.

\section{France}

General health strategies related to the pandemic: The first three official COVID-19 cases in France were listed on 24th January 2020 [7]. The Organization of the Response of the Health System in exceptional health situations (Organisation de la Réponse du système de SANté en situations sanitaires exceptionnelles) launched a plan for Epidemic and Biologic Risks (Risques Épidémiques et Biologiques) [9]. Stage one of this plan, called ORSAN-REB, was launched on 23rd February to limit the introduction of the SARS-CoV-2 into France. Six days later, Stage two was started to contain the epidemic by screening suspect cases and treating possible and confirmed cases in "COVID-19-ready" hospitals (individual focus). Stage three, also known as the epidemic stage, was launched on 14th March [7] and the French population was finally confined two days later [7], after 6663 cases and 148 deaths. At this stage, given the active circulation of SARS-CoV-2, the strategy shifted to a collective approach based on three main axes: (1) to protect vulnerable populations, (2) to treat mild patients in ambulatory care [10], and (3) to treat serious cases in hospital [9]. Nevertheless, the protection of vulnerable populations had begun in Stage two and all visits to nursing home residents were prohibited from 11th March. During this period and the following three weeks, even if the mortality rate increased in nursing homes, the first deaths in nursing homes were not communicated until 1st April. On date of the revision on July 1, 2020, 23\% of those infected (confirmed with RT-PCR, 38,107 out of
165,719 cases) and $35 \%$ of those who died (10,497 out of 29,861 deaths) were $\mathrm{NH}$ residents, indicating a case fatality rate of $27.5 \%$.

Impact of COVID-19 on health inequity: At the beginning of the epidemic stage, the anticipation of a persistent lack of beds in intensive care units (ICUs) led to a reflection on the prioritization of care according to age. Thus, on 19th March the Ile-de France Regional Health Agency relayed recommendations about the decision to admit to ICU published by the French Society of Anesthesiology and Resuscitation, in which age was clearly a criterion of decision (although without a specified cut-off age) [11]. Fortunately, these considerations were reported in mainstream media, which led to strong reactions from the population and to one of the first statements of the French National Academy of Medicine against ageism [12]. With the intervention of the president of the French Society of Geriatrics and Gerontology, hammering on the importance of self-determination in older adults, this criterion was finally abandoned on 23rd April.

\section{Italy}

General health strategies related to the pandemic: The first confirmed case of SARS-CoV-2 infection in Italy was identified on 18th February 2020 in the town of Codogno (Lombardy Region) [13]. This case was soon found not to be isolated, and the diffusion of the SARS-CoV-2 in the area was more rapid than expected. In the following days, social distancing measures were applied, culminating in a regional, and subsequent national, lockdown [14]. The magnitude of events together with a general unpreparedness of the healthcare system made the COVID-19 pandemic particularly burdensome in Italy. In particular, several geriatric settings (e.g., nursing homes) found themselves completely abandoned, with major difficulties in managing their frail older patients [15]. At the same time, hospitals (especially the emergency departments) were overwhelmed by patients with respiratory conditions, requiring clinicians to take tough decisions in an emergency characterized by lack of resources (e.g., ventilators) [16].

Impact of COVID-19 on health inequity: In this scenario, many critical decisions were taken without supporting evidence (given the novelty of this coronavirus), support from ad hoc specialists, or adequate time to formulate a sufficiently informed plan. In other words, many of the choices made at the time might be at risk of being considered unethical [16]. For example, the Italian Society of Anesthesia, Analgesia, and Intensive Care (SIAARTI) published the "Clinical ethics recommendations for the allocation of intensive care treatments in exceptional, resource-limited circumstances", in which there is explicit mention about the role of age in the decision-making process: "An age limit for admission to the ICU may ultimately need to be set. The 
underlying principle would be to save limited resources which may become extremely scarce for those who have a much greater probability of survival and life expectancy, in order to maximize the benefits for the largest number of people"; and "Together with age, the comorbidities and functional status of any critically ill patient presenting in these exceptional circumstances should carefully be evaluated. A longer and, hence, more 'resource-consuming' clinical course may be anticipated in frail older patients with severe comorbidities, as compared to a relatively shorter and potentially more benign course in healthy young subjects" [17]. Although this document suggests consideration of comorbidities and functional status of the patients when taking decisions about COVID-19 management, age is the first criterion mentioned, the easiest/quickest factor to be obtained in an emergency situation, and the logical parameter for resource allocation in an ageistic society such as the one we live in. The adoption of age as a cornerstone criterion for clinical decisions during the pandemic is also implicitly present in those directives that tried to limit access to hospital care for nursing home residents. Moreover, the discharge of hospital patients- possibly with COVID-19to nursing homes (where the frailest and most vulnerable individuals live) was maintained, justified by the need for decompression of emergency departments. Again, the traditional stigma affecting nursing homes determined the way in which the system reacted to the pandemic [18].

\section{Poland}

General health strategies related to the pandemic: In Poland, the SARS-CoV-2 outbreak started on 4th March 2020 with the so-called "Patient Zero", a 66-year-old man who travelled by bus from Germany to Poland. As of 17th June, there were 30,701 confirmed cases of COVID-19 in Poland. Unfortunately, as of June 2020, Poland lacks regularly updated, publicly available information on the age structure of diagnosed, recovered and deceased persons with COVID-19, including separate reports for those aged 65 and older. With regard to national guidelines, "call to action" documents for healthcare workers, patients and their families were launched by the College of Family Physicians in Poland together with the Polish College of Geriatricians (24th March) [19] and the Polish Society of Gerontology (25th March) [20]. On 9th April, the Polish Psychiatric Association published a comprehensive set of recommendations for patients, caregivers and physicians concerning the appropriate approaches in patients with dementia during the COVID-19 epidemic [21]. In mid-March 2020, the national health care system adapted to the changing requirements to sustain medical care. As a result, at the beginning, 19 single-purpose infectious disease hospitals were established across the country for COVID-19 patients, supplemented by
70 infectious disease wards. None of these has been dedicated to the care of older patients exclusively.

Impact of COVID-19 on health inequity: As of June 2020, chronic comorbidities and patients' treatments are managed by way of tele-counselling whenever possible; no additional support or modality to facilitate healthcare services contact has been offered for older patients. No specific model of care has been proposed for the most vulnerable older adults (e.g., patients with dementia, frail or disabled). However, a telephone help-line for older persons has been established, dedicated to tackling the anticipated problems of depression and other mood disorders. National and local-level health care authorities have been using television and radio broadcast networks, social media and press for information campaigns covering SARS-CoV-2 prevention and risks. The first educational campaign concerning SARS-CoV-2 in Poland had been introduced before the first case was confirmed, and was followed by more detailed and specific advice. No specific recommendations to older persons in general, beyond the WHO recommendations, were issued (Fig. 1). Apart from this advisory position, no particular senior-targeted action was taken at the community level (including social support, meals-on-wheels, extra financial support for those affected by SARS-CoV-2, etc.). Day-to-day support is often provided by formal or informal volunteers, mobilized and coordinated by means of social networking.

\section{Spain}

General health strategies related to the pandemic: Spain is third in Europe for the number of COVID-19 cases, as of 8th June 2020. Despite the news coming from Italy, no prevention policies were implemented in Spain until 15th March. The impact of the COVID-19 pandemic was greater than in neighboring countries such as Portugal, which closed public facilities at the same time, but with the substantial difference that Portugal had recorded 245 cases of COVID-19 and no deaths at the date of closure of international borders (16th March), while Spain had already recorded 9191 cases and 309 deaths [7]. Although the outbreak began in early March, the first cases of COVID-19 were confirmed in the Canary and Balearic Islands in mid-February and mainly involved tourists from Germany and Italy [22]. The spread of the virus and the impact in number of cases was uneven throughout Spain, with Madrid and Barcelona being the most affected areas [22], where health resources soon collapsed. Redistribution of hospital resources and relocation of health professionals was needed. The capacity of the ICUs could not keep up with the increasing demand, and they were expanded to double or triple capacity. The number of ICU beds for 100,000 habitants in Spain was 9.7 before COVID19 , in contrast to Germany's 33.9 ICU beds per 100,000 population [7]. In the city of Madrid, the pavilions of the 
city fair were converted into a field hospital to accommodate 5000 patients. Other infrastructures, such as hotels and municipal gyms, were converted into hospitals for the control of post-acute COVID-19 patients [23].

Impact of COVID-19 on health inequity: As scientific societies and ethics committees developed recommendations to optimize the available resources, age was used as the primary variable in decision making in many of these recommendations, such as the protocols from the Spanish Society of Intensive Care Medicine [24]. The Spanish Ministry of Health published action protocols for hospitals without specifically addressing the management of the older population. One of the most notable emergencies during the COVID-19 pandemic was that of nursing homes [25]. The large number of people living together and sharing common areas facilitated the spread of SARS-CoV-2; the patient profile, with high comorbidity, dependence and care needs, made them more vulnerable to the virus. Finally, the lack of resources in nursing homes, such as lack of access to intravenous treatment, oxygen therapy, nurses or doctors, or facilities to treat acute patients, made the situation unsustainable [25]. On 25th May, no exact numbers were available for cases of SARS-CoV-2 infection in LTCF in Spain; nevertheless, of the 26,860 total deaths related to COVID-19, 17,730 were in LTCF, which represent $66 \%$ of the COVID-19 related deaths in the country [8]. In this context, the Spanish Ministry of Health published hygiene recommendations and isolation measures for nursing homes. However, these did not specify clinical management or referral criteria [25]. In Catalonia, the Department of Health developed an action protocol in nursing homes stating: "It is not necessary to refer probable or confirmed cases to the hospital in a situation of advanced chronic disease, as a limitation of the therapeutic effort has been decided" [26]. Nonetheless, no PPE or medical supplies for the management of new COVID-19 cases were provided to nursing home facilities, most of which are private and understaffed [27]. It is true that referrals should be reduced as much as possible, but an advanced chronic disease cannot be a criterion for exclusion without previous assessment of functional status and life prognosis. As the health crisis progressed, primary care was instructed to coordinate with nursing homes, but given the results this approach was insufficient [25].

\section{United Kingdom}

General health strategies related to the pandemic: At the national level, all those deemed "clinically extremely vulnerable" were sent a letter explaining the need to "shield" for 12 weeks [28-30]. Otherwise, social distancing was advised, with people at "moderate risk" or "clinically vulnerable" to take particular precautions, which included all people older than 70 years, or with diabetes, asthma and other chronic conditions. Confusion between clinically "vulnerable" and "extremely vulnerable" was perpetuated in public statements, leading to accusations at the government of being ageist [30]. The British Geriatrics Society (BGS) has curated a helpful "Coronavirus and older people" Webpage with the most pertinent of many new and updated clinical guidelines [31]. This includes some of the National Institute for Health and Care Excellence (NICE) rapid COVID-19 guidelines [32], as well as several specific Good Practice guides and fact sheets written by the BGS, such as "Managing the COVID-19 pandemic in care homes". In line with the UK's general approach, age has not been a specific point in COVID-19 guidelines. The Clinical Frailty Scale was introduced in "COVID-19 rapid guideline: critical care in adults" (NG159) as a decision aid regarding whether patients would benefit from intensive care treatment. One of its stated purposes was to "enable services to make the best use of National Health System (NHS) resources", albeit caveated with the need to exercise judgement and a reminder that compliance was not mandatory. There may be some positive legacies from new guidelines, such as improved appreciation of the frailty concept amongst non-geriatricians, and community palliative care provision. At the point of writing, 8th June 2020, the UK has had 287,399 confirmed cases of COVID-19, and 40,597 COVID-19 "associated" deaths [7]. The total excess mortality, however, is currently estimated at 59,500 people, $65 \%$ over usual rates for this time of year and one of the world's highest [7]. Between May 15-17, Scotland reported 5,652 people with confirmed SARS-CoV-2 infection in LTCF (no data available for England and Wales). In Scotland, of the total 3,213 deaths related to SARS-CoV-2, 1,438 (44\%) were in LTCF. In England and Wales, of the total 34,978 deaths related to COVID-19, 7401 (21\%) were in LTCF [8].

Impact of COVID-19 on health inequity: Primary care was "reminded" to proactively have discussions with patients regarding their treatment escalation wishes. Robust responses from the Care Quality Commission, charity sector, and necessary clarifications and retractions followed. In April, NHS England recommended that primary care can "move immediately to total digital triage followed by remote management wherever possible and appropriate..." [33]. Non-digital users were able to access telephone support, but the push to online services has created a perceived barrier for some older people. Arguably the most widespread implication for this population, however, was the early political emphasis on prioritizing hospitals, without sufficient safeguards for those residing/working in care home and social care sectors. The decision in March to empty NHS hospitals was alongside Department of Health and Social Care guidelines stating: "Negative tests are not required prior to transfers/admissions into the care home" [34], despite unreliable PPE deliveries to care homes even by early May. 
Discharging people from hospitals to care homes without SARS-CoV-2 testing had a devastating impact. By 10th May, $36 \%$ of care homes in England and 59\% in Scotland had a suspected/confirmed outbreak of COVID-19 [34]. Figures for those receiving domiciliary care are more difficult to get, but in England between 10th April and 8th May, there were 3161 deaths, 1990 more than the 3-year average for the same time period [35]. Hospitals and care homes followed national guidance to restrict visiting, and, therefore, many died alone or with only staff members present, and social distancing has also had an impact on the bereavement process.

\section{Initiatives and challenges for the COVID-19 pandemic and beyond}

Support from institutions and health care providers should aim to address the specific needs of older patients. Social adjustments have been made. In the UK, for example, early headlines highlighted difficulties with older adults getting food items, resulting in some supermarkets introducing special shopping hours only for them, and those with "shielding" letters could get priority online food deliveries. A need for digital connectivity and bank cards, or family/social support, was often needed to help access resources online. In many countries, the improved social and digital connectivity has been a positive outcome for some. Otherwise mental health, and physical, cognitive and social deconditioning are major concerns, as well as delays to elective surgery and resultant deterioration in health.

Another shared concern was the lack of attention to providing adequate materials, medications and human resources to nursing homes. Right to health is universal; this right cannot be subject to age. A related issue was the lack of guidelines for the management and hospital transfer of older patients with COVID-19, along with the subsequent isolation, infection control for residents, staff and visitors, and institutional and individual hygiene measures, as well as consistent reporting protocols. Only reports from Poland and UK mentioned the development of policies, national guidelines and protocols. Development and systematic updating of harmonized European guidelines would provide a shared baseline of good practice, a benefit for all European countries that could save lives, time and confusion.

\section{Role of primary care during the SARS-Cov-2 crisis}

Media attention during the COVID-19 pandemic has been mainly focused on the hospital centers. However, primary care and community pharmacy have played crucial, less publicized roles. The WHO recommendations on the role of primary care during the COVID-19 pandemic (Fig. 1) highlight the importance of rapid diagnosis (given the risk of SARSCoV-2 transmission between contacts), health education for the population to prevent infection, and the maintenance of essential health services in the general population [1].

However, in many countries, especially those hardest hit by the pandemic, primary care has played more of a "buffer" role to desaturate hospital emergency departments, address collective anxiety and avoid if possible the admission of patients with chronic decompensated diseases [36]. Relocation of health professionals from primary care to hospitals limited the power of action against SARS-CoV-2 by primary care centers and overlooks the importance of primary care in guaranteeing continuity of care.

New models have been developed to cope with the absence of physical consultations. Web-based telemedicine (e.g., webpages, apps, etc.) and telephone calls have been given priority, whilst home medical visits have been reserved when physical examinations are required [37]. These strategies have served to follow SARS-CoV-2-positive patients in self-isolation but failed to fulfill one of the main objectives of primary care, e.g. to look after older people with chronic pathologies. Some older people may thus have suffered from a reduction in control of chronic diseases, as well as struggling with fear and anxiety during the pandemic. Chronic disease management has also moved almost entirely to remote consultations.

On the other hand, several interesting initiatives have been taken across Europe because of the COVID-19 pandemic, such as an increased move to digital triage and liberalization of home oxygen therapy prescriptions (allowing earlier hospital discharges, or in some cases avoidance of hospital admission). Attention has been focused on tasks that add value to clinical practice by filtering the medical consults, distinguishing those that can be solved online from those needing face-to-face attention [38]. There has also been improved collaboration with community healthcare-specific groups and services and thirdsector agencies such as independent charities.

The role of primary care across Europe during the COVID-19 pandemic has frequently been limited by the centralization of the crisis in hospital settings, and by the lack of facilities and resources to combat SARS-CoV-2. In a context of economic recession following the shutdown of the European economy, primary care should be strengthened with sufficient resources to cope with the follow-up and detection of new cases of COVID-19, and also to meet the ongoing needs of comorbid patients.

\section{Discussion}

The six countries that participated in this project implemented the general WHO recommendations in the first or second week of March 2020 (Fig. 1) [1]. A lack of 
government planning, the collapse of national health systems, and a scarcity of material and human resources occurred in most of these countries, particularly during March and April 2020.

\section{COVID-19 points out an urgent need for higher standards of care in nursing homes in Europe}

Older adults were the most severely affected population in Belgium, France, Italy, Spain, and the UK [39], particularly those living in nursing homes (no data available for Poland). All authors pointed out the scarcity of material and human resources (Fig. 2). In 2011, the International Association of Gerontology and Geriatrics launched the 'Global Agenda for Clinical Research and Quality of Care in Nursing Homes', which highlighted the general lack of specific medical education in long-term care in most of the European countries and the urgent need to harmonize guidelines across Europe [40]. The Special Interest Group (SIG) in Long Term Care of the EuGMS states that shortcomings reflected in the 2011 report have still to be resolved and highlights their negative impact on the management of nursing homes during the COVID-19 pandemic [41]. Unified and targeted actions are required. It would be crucial to provide common guidelines about the protective measures to prevent SARS-CoV-2 infections in nursing homes, the priorities (material and human resources) in dealing with outbreaks, the measures for testing and monitoring both older residents and workers, and measures to control infection once it has entered a facility (e.g. isolation protocols) and ensure tailored acute and/or palliative measures for residents with COVID-19 [42].

\section{Right to health and participation in the decision-making process}

Belgium, Spain and the UK increased their efforts to implement a treatment escalation plans, which included preventive decisions regarding theappropriateness of transfer from nursing homes to hospitals in case of clinical worsening (Fig. 2). These decisions were not based on age, but rather on functional status, comorbidities, life expectancy and therapeutic options. In Belgium, the assessment of baseline frailty was included in the criteria to transfer patients to hospitals. In the UK, the BGS published a position statement to emphasize the need for using standardized meaningful measures and outcomes such as frailty and function rather than age.

Older people are a heterogeneous population and need multidimensional policies based on equality, high quality of care and intergenerational exchange to ensure high ethical standards and preservation of personal dignity. It is necessary to involve patients, caregivers, nursing home directors and stakeholders in the decisions that directly affect them, developing patient- and care-centered policies [43-45].
Health care is a basic human right, and access to adequate health resources must be guaranteed for all, regardless of functional state, comorbidities and frailty [16, 44]. Age discrimination can be seen in this pandemic both in the poor opportunities for participation by older people in the decision-making that affects them and in the inequities in their access to healthcare, where decisions often have been based solely on age $[46,47]$. The SARS-CoV-2 health crisis highlights the need for health decision-making protocols suitable to be applied in clinical practice and based on scientific evidence [48]. Specifying steps to support the transition of the social and health model from disease-focused medicine to person-focused medicine might help to address the unmet needs of older people $[14,46]$.

Age has often been identified as the strongest risk factor for negative outcomes in medicine, independent of the context and disease of interest. Nevertheless, chronological age is a construct that does not necessarily mirror biology, a concept increasingly recognized but not yet incorporated sufficiently into widespread medical practice. Focusing on what really is a result of the aging process (e.g., clinical conditions, physical and mental function) may better estimate the individual's reserves and promote a person-tailored plan of the intervention [18].

\section{Social inclusion and solidarity under conditions of physical distancing}

The social distancing measures implemented by the majority of countries to stop the spread of SARS-CoV-2 have inevitably had an impact on the older population. Both loneliness (17\% in women, $9 \%$ in men over 60 living alone) and poor social support have been problems in older populations before, during and after COVID-19 pandemic [49, 50]. In an attempt to reduce risks to older people, many hospitals and nursing homes restricted visits, which may also have had an adverse effect on the psycho-cognitive and physical state of older people [49].

In the community, formal arrangements for social support measures were not always instigated alongside distancing guidance, such as ensuring that home care services and food purchases were not interrupted. However, on a positive note, many communities have come together, charities such as Age UK have been invaluable, and some older people are benefiting from an increase in confidence with online and social networking. Some of these benefits may be longlasting (Fig. 2).

\section{Necessity of adequate, correctly funded care and support services for older adults}

The COVID-19 crisis has revealed discriminatory attitudes towards older people due to chronological age [50]. Despite 
the high pressure on the healthcare system and the availability of resources, decision-making and treatment options should be based on objective ethical clinical guidelines and parameters, and not solely on age. Therefore, early identification of older individuals at higher risk by tailored, comprehensive geriatric assessment, along with the overall goal of providing the highest quality of care, should be prioritized over chronological age in clinical decision-making and the development of health policies [16]. Geriatricians need to work together with other medical specialist societies, where some of the ageism is perpetuated, along with older people themselves and society at large, to change these attitudes.

\section{Need to expand participation by older adults, share good practice and harness knowledge and data}

Our initiative is aligned with the efforts of the UN, WHO and EuGMS, among others, to share good practice and gather knowledge and data. Several predictive models to anticipate the behavior of the disease and counteract this new threat are in progress [6]. Moreover, new methodological approaches, such as the Integrated Approaches to Testing and Assessment (IATA), which bring together current knowledge in different disciplines might be helpful to gather data and develop safe, efficient therapeutic strategies to combat this disease.

\section{Strengths and limitations}

The strengths of this work include the interdisciplinary nature of the relatively large number of specialists in Geriatrics and Primary Care physicians from different European groups who reported on their countries' experience, offering a broad point of view of the European healthcare situation during the pandemic from the healthcare professionals' point of view. The authors acknowledge that the reporting is anecdotal, not systematic, may have some biases, and inevitably can only reflect partial observations and reflections of the authors on the needs, actions and policies described. Furthermore, the opinion of each medical setting might differ compared to those in another center or region of the country, as many countries have decentralized health systems.

\section{Key pragmatic actions for further improvement}

- Guarantee institutional support for long-term care facilities and develop specific, harmonized European guidelines for the management and hospital referral of older patients with COVID-19, as well as protocols for action within centers registering positive cases for SARS-CoV-2 (e.g., case isolation, staff infection control, visitor restriction policies and hygiene measures). In addition, the supply of PPE, medication stocks and other equipment needed to maintain proper clinical management at these centers should be ensured; if needed, medical support units should be made available both in situ as well as by telematic channels.

- Ensure access to health resources and avoid diagnostic and therapeutic decisions based solely on age. The involvement of the patient in clinical decision-making should be enforced whenever possible, taking their values, preferences and care goals as the cornerstone (empowerment). In case intensive care hospitalization or mechanical ventilation is needed, decision-making should be individualized and take into consideration aspects such as functional status prior to the onset of acute illness, frailty, life expectancy and co-morbidity. Specific guidelines for the management and hospital treatment of older COVID-19 patients should also be considered.

- Guarantee support for those providing home care services, with similar protection in terms of PPE provision and sick pay [5]. Address the disparities in pay and job security between health care and social care workers. Safeguard social support services in an older population, with home assistance or meals and cleaning services, which are often what determine their ability to live alone at their homes. Offer systems to avoid social isolation, such as telephone support or apps for social interaction, thus favoring mental resilience and avoiding as far as possible a negative psychological impact of quarantine and social distancing [7]. Promote initiatives for psychological, medical or social support for people with dementia and their caregivers in case the day centers and third sector activities are closed.

- Support primary care to be the gateway to the health system for new cases of COVID-19, providing it with diagnostic tools such as RT-PCR and serology for fast diagnosis and contact tracing. The availability of health professionals for the follow-up of chronic diseases should be guaranteed.

\section{Conclusions}

Although we have learned some lessons, there is room to improve with the perspective of a possible second wave of COVID-19. Some of the lessons learned are that the COVID-19 pandemic has hit across our society; however, it has not hit all groups with the same intensity. Older people have been the most affected by the virus. This sad reality shows that many of the public policies adopted by different administrations against the COVID-19 pandemic did not adjust to the needs of older adults, a population requiring 
both inclusive and targeted measures. After the pandemic, key questions will remain as to how prevention or provision of PPE failed, questions which society must answer.

Points to improve have been identified. One hopes that this pandemic will enable some positive changes in future, both in terms of the value society places on care workers and how we as a society support and treat our older generation. However, much of the narrative around COVID-19, including the classification of older people as "vulnerable" or recommendations "based on chronological age", may challenge this hope. Our goal is to educate healthcare professionals on the scientific evidence behind comprehensive geriatric assessment and biological age in decision-making, and to address widespread perceptions of the predominant importance of chronological age.

Acknowledgements The authors gratefully acknowledge Elaine Lilly $\mathrm{PhD}$, for language revisions and unfailing support.

Author contributions $\mathrm{OM}, \mathrm{CA}, \mathrm{AB}, \mathrm{AC}, \mathrm{PJG}, \mathrm{SG}, \mathrm{SH}, \mathrm{KP}, \mathrm{KP}, \mathrm{NP}$, GS, MS and EV wrote the manuscript; OM, DSR, EM, and SH corrected the manuscript. All co-authors read and approved the final version of the manuscript.

Funding This project has been partially funded by a grant from 'Secretaria d'Universitats i Recerca del Departament d'Empresa i Coneixement de la Generalitat de Catalunya'.

\section{Compliance with ethical standards}

Conflict of interest The author declares that they have no cometing of interest.

Ethical approval Not applicable.

Informed consent Not applicable.

\section{References}

1. World Health Organization (2020) Coronavirus disease 2019 (COVID-19) situation report-101. World Health Organization, Geneva

2. Verity R, Okell LC, Dorigatti I et al (2020) Estimates of the severity of coronavirus disease 2019: a model-based analysis. Lancet Infect Dis 20:669-677. https://doi.org/10.1016/S1473 -3099(20)30243-7

3. Abbatecola AM, Antonelli-Incalzi R (2020) Editorial: COVID-19 spiraling of frailty in older Italian patients. J Nutr Health Aging 24:453-455. https://doi.org/10.1007/s12603-020-1357-9

4. The Impact of COVID-19 on older persons (2020). https://unsdg un.org/sites/default/files/2020-05/Policy-Brief-The-Impact-ofCOVID-19-on-Older-Persons.pdf. Accessed 20 Aug 2020

5. Statement of the EuGMS Executive Board on the COVID-19 epidemic - EuGMS. https://www.eugms.org/news/read/article/489. html. Accessed 8 Oct 2020
6. Scudellari M (2020) How the pandemic might play out in 2021 and beyond. Nature 584:22-25. https://doi.org/10.1038/d4158 6-020-02278-5

7. European Centre for Disease Prevention and Control (2020). An agency of the European Union. COVID-19 situation update for the EU/EEA and the UK, as of 24 June 2020 [Internet]. ECDC press room. https://www.ecdc.europa.eu/en/cases-2019-ncov-eueea. Accessed 24 Jun 2020

8. Ecdc (2020) Surveillance of COVID-19 at long-term care facilities in the EU/EEA. https://www.skillednursingfacilities.org/resou rces/what-are-skilled-nursing-facilities-/. Accessed 20 Aug 2020

9. Guide méthodologique Covid-19 (2020). https://solidarites-sante .gouv.fr/IMG/pdf/guide_methodologique_covid-19-2.pdf\#page9 . Accessed 25 May 2020

10. Sanchez-Rodriguez D, Annweiler C, Gillain S et al (2020) Implementation of the integrated care of older people (ICOPE) app in primary care: new technologies in geriatric care during quarantine of COVID-19 and beyond. J Frailty Aging 2020:1-2. https://doi. org/10.14283/JFA.2020.24

11. Azoulay E, Beloucif S, Vivien B, Guidet B, Pateron D, Le Dorze M (2020) Décision d'admission Des Patients En Unités de Réanimation et Unités de Soins Critiques Dans Un Contexte d'épidémie à Covid-19. Societé Française d'Anesthésie Réanimation. https ://www.iledefrance.ars.sante.fr/system/files/2020-03/010_ARSId F-CRAPS_2020-03-19_Doctrine_Criteres-admission_Soins-Criti ques.pdf. Accessed 8 Oct 2020

12. Âgisme et tensions intergénérationnelles en période de Covid-19. Académie nationale de médecine I Une institution dans son temps. (2020). https://www.academie-medecine.fr/communique-de-lacad emie-nationale-de-medecin. Accessed 26 May 2020

13. Signorelli C, Scognamiglio T, Odone A (2020) COVID-19 in Italy: impact of containment measures and prevalence estimates of infection in the general population. Acta Bio Medica Atenei Parm 91:175-179. https://doi.org/10.23750/ABM.V91I3-S.9511

14. Riccardo F, Ajelli M, Andrianou X et al (2020) Epidemiological characteristics of COVID-19 cases in Italy and estimates of the reproductive numbers one month into the epidemic. medRxiv. https://doi.org/10.1101/2020.04.08.20056861

15. Trabucchi M, De Leo D (2020) Nursing homes or besieged castles: COVID-19 in northern Italy. Lancet Psychiatry 7:387-388. https://doi.org/10.1016/S2215-0366(20)30149-8

16. Cesari M, Proietti M (2020) COVID-19 in Italy: ageism and decision making in a pandemic. J Am Med Dir Assoc 21:576. https:// doi.org/10.1016/J.JAMDA.2020.03.025

17. Vergano M, Bertolini G, Giannini A et al (2020) Clinical ethics recommendations for the allocation of intensive care treatments in exceptional, resource-limited circumstances: the Italian perspective during the COVID-19 epidemic. Crit Care 24:165. https://doi. org/10.1186/s13054-020-02891-w

18. Yourman LC, Lee SJ, Schonberg MA et al (2012) Prognostic indices for older adults: a systematic review. JAMA 307:182-192. https://doi.org/10.1001/jama.2011.1966

19. Medycyna Praktyczna (2020) Geriatria. List otwarty Zarządu Głównego Polskiego Towarzystwa Gerontologicznego [Internet]. Liszki: Medycyna Praktyczna. https://www.mp.pl/geriatria/aktua lnosci/231585,list. Accessed 17 Jun 2020

20. Kolegium Lekarzy Rodzinnych w Polsce. \#1. Apel KLR i KLSGeriatrii 24032020 (1).pdf [Internet]. Warszawa: Kolegium Lekarzy Rodzinnych w Polsce (2020). https://klrwp.pl/strona/669/ apel-klr-i-seniorow/p. Accessed 17 Jun 2020

21. Polskie Towarzystwo Psychiatryczne. Rekomendacje PTP: Epidemia SARS-COV-2 a populacja osób z otępieniem [Internet]. Warszawa: Polskie Towarzystwo Psychiatryczne; [updated 2020 
April 9; cited 2020 June 17]. Available from: https://psychiatri a.org.pl/aktual

22. Instituto de Salud Carlos III (2020) Ministerio de Ciencia e Innovación. Gobierno de España. Informe situación COVID-19 en España a 11 de febrero. 2020. https://www.who.int/dg/speeches/ detail/who-director-general-s-remarks-at-the-media-briefing-on2019-ncov-on-11-february-. Accessed 8 Oct 2020

23. Rascado P, Ballesteros MA, Bodí MA et al (2020) Plan De Contingencia Frente a La Pandemia Covid-19. Soc Española Enferm Intensiva y Unidades coronarias. www.seeiuc.org. Accessed 8 Oct 2020

24. Manzano A, Labayen F, Bitor SC et al (2020) Recomendaciones éticas para la toma de decisiones en la situación excepcional de crisis por pandemia Covid-19 en las Unidades de Cuidados intensivos-Cuidados Críticos. Recomendaciones sobre Limitación. www.semicyuc.org. Accessed 8 Oct 2020

25. Deusdad B (2020) COVID-19 and Nursing Homes 'crisis in Spain : Ageism and Scarcity of Resources . El COVID-19 y la Crisis de las Residencias de Mayores en España : Edadismo y Precariedad España : Edadismo y Precariedad

26. Servei Català de la Salut (2020) Guia d'actuació enfront de casos d'infecció pel nou coronavirus SARS-CoV-2 a les residències. https://canalsalut.gencat.cat/web/.content/_A-Z/C/coronaviru s-2019-ncov/material-divulgatiu/guia-actuacio-residencies.pdf. Accessed 8 Oct 2020

27. Tarazona-Santabalbina FJ, Martínez-Velilla N, María Teresa Vidán JAG-N (2020) COVID-19, adulto mayor y edadismo: errores que nunca han de volver a ocurrir. Rev Esp Geriatr Gerontol. https://doi.org/10.1016/j.regg.2020.04.001

28. Who's at higher risk from coronavirus (COVID-19)—NHS. https ://www.nhs.uk/conditions/coronavirus-covid-19/people-at-highe r-risk/whos-at-higher-risk-from-coronavirus/. Accessed 29 June 2020

29. National Health System UK (2020) Information for GPs advising both shielding and non-shielding patients on support available during the COVID-19 pandemic. https://www.england.nhs.uk/ coronavirus/wp-content/uploads/sites/52/2020/03/C0429-gpsupport-information-for-shielding-and-non-shieldi. Accessed 8 Oct 2020

30. Pippa Allen-Kinross. What is 'shielding' and who needs to do it? - Full Fact. https://fullfact.org/health/coronavirus-shielding-socia 1-distancing/. Accessed 8 Oct 2020

31. British Geriatrics Society. Coronavirus: advice to older people. https://www.bgs.org.uk/coronavirus-advice-to-older-people. Accessed 29 June 2020

32. National Institute of Health and Care Excellence. About Coronavirus (COVID-19). https://www.nice.org.uk/covid-19. Accessed 29 June 2020

33. National Health System UK (2020). Advice on how to establish a remote 'total triage' model in general practice using online consultations. https://www.england.nhs.uk/coronavirus/wp-conte nt/uploads/sites/52/2020/03/C0098-Total-triage-blueprint-April -2020-v2.pdf. Aaccessed 8 Oct 2020

34. Robert Booth. Government rejected radical lockdown of England's care homes I World news I The Guardian. https://www. theguardian.com/world/2020/may/28/government-rejected-radic al-lockdown-england-care-homes-coronavirus. Accessed 29 June 2020

35. Ian Trenholm. Sharing insight, asking questions, encouraging collaboration: CQC publishes first insight document on COVID-19 pressures I Care Quality Commission. https://www.cqc.org.uk/ news/stories/sharing-insight-asking-questions-encouraging-colla boration-cqc-publishes-first-insight-document-on-covid-19-press ures. Accessed 29 June 2020

36. Kretchy IA, Asiedu-Danso M, Kretchy J-P (2020) Medication management and adherence during the COVID-19 pandemic: perspectives and experiences from low-and middle-income countries. Res Soc Adm Pharm. https://doi.org/10.1016/j.sapha rm.2020.04.007

37. Goodman-Casanova JM, Dura-Perez E, Guzman-Parra J et al (2020) Telehealth home support during COVID-19 confinement for community-dwelling older adults with mild cognitive impairment or mild dementia: survey study. J Med Internet Res 22:e19434. https://doi.org/10.2196/19434

38. Sociedad Española de Medicina Familiar y Comunitaria (2020). Fase de transición de la pandemia por SARS-CoV-2 en Atención Primaria - semFYC. https://www.semfyc.es/formacion-y-recur sos/fase-de-transicion-de-la-pandemia-por-sars-cov-2-en-atenc ion-primaria/. Accessed 8 Oct 2020

39. Li W, Fang Y, Liao J et al (2020) Clinical and CT features of the COVID-19 infection: comparison among four different age groups. Eur Geriatr Med 1:3. https://doi.org/10.1007/s41999-02000356-5

40. Tolson D, Rolland Y, Andrieu S et al (2011) International association of gerontology and geriatrics: a global agenda for clinical research and quality of care in nursing homes. J Am Med Dir Assoc 12:184-189. https://doi.org/10.1016/j.jamda.2010.12.013

41. O'Neill D, Briggs R, Holmerová I et al (2020) COVID-19 highlights the need for universal adoption of standards of medical care for physicians in nursing homes in Europe. Eur Geriatr Med 1:3. https://doi.org/10.1007/s41999-020-00347-6

42. Szczerbińska K (2020) Could we have done better with COVID-19 in nursing homes? Eur Geriatr Med 1:3. https://doi.org/10.1007/ s41999-020-00362-7

43. Ayalon L, Chasteen A, Diehl M et al (2020) Aging in times of the COVID-19 Pandemic: avoiding ageism and fostering intergenerational solidarity. Journals Gerontol Ser B. https://doi.org/10.1093/ geronb/gbaa051

44. Montero-Odasso M, Hogan DB, Lam R et al (2020) Age alone is not adequate to determine health-care resource allocation during the COVID-19 pandemic. Can Geriatr J 23:152-154. https://doi. org/10.5770/cgj.23.452

45. Lim W, Liang C, Assantachai P et al (2020) COVID -19 and older people in Asia: Asian Working Group for Sarcopenia calls to actions. Geriatr Gerontol Int 20:547-558. https://doi.org/10.1111/ ggi.13939

46. Brooke J, Jackson D (2020) Older people and COVID-19: isolation, risk and ageism. J Clin Nurs 29:2044-2046. https://doi. org/10.1111/jocn. 15274

47. Beauchet O, Fantino B, Annweiler C (2012) The 'ActionResearch' philosophy: from bedside to bench, to bedside again. Int J Clin Pract 66:517-517. https://doi.org/10.111 1/j.1742-1241.2012.02909.x

48. Departament of Economic and Social Affairs (United Nations). Issue Brief on Older Persons and COVID-19: a Defining Moment for Informed, Inclusive and Targeted ResponseUnited Nations For Ageing I United Nations For Ageing. https://www.un.org/devel opment/desa/ageing/news/2020/04/issue-brief-on-older-perso ns-and-covid-19-a-defining-moment-for-informed-inclusive-andtargeted-response/. Accessed 29 June 2020 
49. Archard D, Caplan A (2020) Is it wrong to prioritise younger patients with covid-19? BMJ 369:m1509. https://doi.org/10.1136/ bmj.m1509

50. Previtali F, Allen LD, Varlamova M (2020) Not only virus spread: the diffusion of ageism during the outbreak of COVID-19. J
Aging Soc Policy 32:506-514. https://doi.org/10.1080/08959 420.2020 .1772002

Publisher's Note Springer Nature remains neutral with regard to jurisdictional claims in published maps and institutional affiliations.

\section{Affiliations}

\section{Oriol Miralles ${ }^{1}(\mathbb{D})$. Dolores Sanchez-Rodriguez ${ }^{2,3,4} \cdot$ Esther Marco $^{5}$. Cédric Annweiler ${ }^{6,7,8} \cdot$ Ainhoa Baztan $^{9}$. Évora Betancor $^{1} \cdot$ Alicia Cambra $^{1} \cdot$ Matteo Cesari $^{10,11}$ - Benito J. Fontecha ${ }^{1}$ Jerzy Gąsowski ${ }^{12} \cdot$ Sophie Gillain $^{13}$. Suzy Hope ${ }^{14,15} \cdot$ Katie Phillips $^{16} \cdot$ Karolina Piotrowicz $^{12} \cdot$ Niccolò Piro $^{10} \cdot$ Guillaume Sacco $^{6,7} \cdot$ Edoardo Saporiti $^{10}$. Murielle Surquin $^{16,17} \cdot$ Estel Vall-llosera $^{1}$}

1 Geriatrics and Palliative Care Department, Hospital General de L'Hospitalet de Llobregat-Consorci Sanitari Integral, L'Hospitalet de Llobregat, Av. Josep Molins, 29 L'Hospitalet de Llobregat, 08906 Barcelona, Spain

2 Clinical Research Unit, CHU Brugmann, Brussels, Belgium

3 WHO Collaborating Centre for Public Health Aspects of Musculo-Skeletal Health and Aging, Division of Public Health, Epidemiology and Health Economics, University of Liège, Liège, Belgium

4 Geriatrics Department, Rehabilitation Research Group, Hospital Del Mar Medical Research Institute (IMIM), Universitat Pompeu Fabra, Barcelona, Spain

5 Physical Medicine and Rehabilitation Departament, Parc de Salut Mar. Hospital del Mar Research Institute (IMIM), Universitat Autònoma de Barcelona, Barcelona, Spain

6 Department of Geriatric Medicine and Memory Clinic, Research Center on Autonomy and Longevity, University Hospital, Angers, France

7 UPRES EA 4638, University of Angers, Angers, France

8 Department of Medical Biophysics, Schulich School of Medicine and Dentistry, Robarts Research Institute, The University of Western Ontario, London, ON, Canada
9 Primary Care Center La Florida, Costa Ponent Unit, Institut Català de La Salut, Catalan Health Institute, L'Hospitalet de Llobregat, Barcelona, Spain

10 Geriatric Unit, Fondazione IRCCS Ca' Granda Ospedale Maggiore Policlinico, Milan, Italy

11 Department of Clinical Sciences and Community Health, University of Milan, Milan, Italy

12 Department of Internal Medicine and Gerontology, Faculty of Medicine, Medical College, Jagiellonian University, Kraków, Poland

13 Geriatrics Department, Liège University Hospital, University of Liège, Liège, Belgium

14 Department of Healthcare for Older People, Royal Devon \& Exeter NHS Foundation Trust, Exeter, UK

15 College of Medicine and Health, University of Exeter, Exeter, UK

16 Beacon Medical Centre, Sidmouth, Devon, UK

17 Geriatrics Department, CHU Brugmann, Université Libre de Bruxelles, Brussels, Belgium 